\title{
A CHROMATOGRAPHIC PROCEDURE FOR THE DETERMINATION OF CAROTENOIDS AND CHLOROPHYLLS IN VEGETABLE PRODUCTS
}

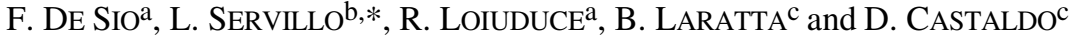 \\ a Department of Tomato Products, Stazione Sperimentale Industria Conserve Alimentari, \\ Via Nazionale 121/123, 84012 Angri (SA). Italy \\ bepartment of Biochemistry and Biophysics, II University of Naples, \\ Via Costantinopoli 16, 80138 Napoli. Italy \\ ${ }^{\mathrm{c}}$ Stazione Sperimentale Industria Essenze e Derivati Agrumari, \\ Via Generale Tommasini 2, 89127 Reggio Calabria. Italy
}

(Received: 7 December 2000; accepted 20 June 2001)

\begin{abstract}
Pigments, such as carotenes, xanthophylls and chlorophylls, were extracted from both vegetables and their industrial products by using a 2:1 (v/v) dichloromethane/methanol solution. To separate and quantify the components in the extraction mixture, a HPLC analysis on reversed phase $\mathrm{C}_{30}$ column and binary gradient, made of methanol/water solution and dichloromethane, was employed. This gradient appears to have some advantages over other reported methods, which utilize reversed phase $\mathrm{C}_{30}$ column, in terms of resolution and analysis time. The linearity range of the detection response, the chromatographic resolution of a standard mixture constituted of lutein, zeaxanthin, trans- $\beta$-apo- 8 '-carotenal, $\beta$-cryptoxanthin, chlorophyll-b, $\alpha$-carotene, chlorophyll-a, $\beta$-carotene, lycopene and the conditions for the complete extraction of those substances from the vegetable matrix were investigated. Both retention time and peak area reproducibility showed an average variation coefficient of about $2 \%$ for all the analyzed compounds. As a consequence of the good chromatographic separation of chlorophylls from carotenoids, sample saponification was found unnecessary when analyzing green vegetable products. Finally, to illustrate the applicability of the method, the presence of carotenoid esters in tomato and orange products was examined.
\end{abstract}

Keywords: carotene, carotenoids and HPLC, chlorophyll, lycopene, tomato, orange products

Carotenoids represent a wide class of natural pigments which have received considerable attention in the last years for their possible role in the prevention of many human diseases. The carotenoids can be classified in two main groups, i.e. carotenes, which are unsaturated hydrocarbons, and their oxygenated derivatives, xanthophylls (or

* To whom correspondence should be addressed.

Fax: +39-081-5665863; E-mail: luigi.servillo@unina2.it 
oxycarotenoids). From biological point of view, one of the main properties attributed to carotenoids is that of being anti-oxidant. This arises from the high number of conjugated double bonds in these molecules which quench singlet oxygen atoms, thus inhibiting the peroxide formation in the cellular membrane lipids. It has been found that carotenoid pigments can prevent or slow down the growth of induced skin tumors and it has been reported that the risk of cancer in human beings may be inversely correlated both with the level of retinol in blood and with the dietary intake of $\beta$-carotene (PETO et al., 1981; STAHL \& SIES, 1996). Another important carotenoid function is that of being physiological precursors of vitamin-A. However, for this function the precursor carotenoid has to have an unsubstituded $\beta$-ionone ring and uncharged side-chain. Chain lengthening decreases the provitamin activity. $\beta$-Carotene, the most widespread provitamin-A, with two $\beta$-ionone rings, shows the highest precursor activity and one molecule could generate two molecules of vitamin-A through the central cleavage. Many carotenoids found in fruits result vitamin-A precursors. Noticeably, lycopene, which is particularly abundant in tomato products, does not possess provitamin-A activity. However, among the natural carotenoids, lycopene is the most efficient singlet oxygen quencher (DI MASCIO et al., 1989; CONN et al., 1991) and more active than $\beta$ carotene in suppressing cell proliferation (LEVY et al., 1995). Many chromatographic methods for the analysis of carotenoids in vegetable matrices, which utilize either isocratic or gradient elution, have been developed. The isocratic systems have a lower resolving power and can be useful to separate carotenoids which are in a rather narrow range of polarity (FISHER \& ROUSEFF, 1986; QUACKENBUSH \& SMALLIDGE, 1986; GuILLOU et al., 1993). Gradient systems have a wider range of applications and have been used for carotenoid analysis in vegetable sources such as orange juices (ROUSEFF et al., 1996), olive oil (PsOMIADOU \& TsimIDOU, 1998) or other biological samples (FERRUZZI et al., 1998). In this paper a simple and efficient chromatographic procedure, that employs a binary gradient made of methanol/water solution and dichloromethane, is reported. This method can be useful in food industry quality control for the determination and quantification of the principal carotenoid compounds.

\section{Materials and methods}

\subsection{Reagents and standards}

Potassium hydroxide, sodium hydroxide, anhydrous sodium sulfate, butylated hydroxytoluene (BHT) and triethylamine (TEA) were purchased fron Sigma-Aldrich, Italy, as well as methanol, methylene chloride, diethyl ether and chloroform which were of HPLC grade. Standards of lycopene, $\beta$-carotene, $\alpha$-carotene, trans- $\beta$-apo- 8 'carotenal, chlorophyll-a and chlorophyll-b were obtained from Sigma-Aldrich, Italy; 
lutein (xanthophyll) from Fluka, Italy; zeaxanthin and $\beta$-cryptoxanthin were from Extrasynthese, France. The standard solutions were prepared by dissolving the substances in chloroform containing $0.1 \%(\mathrm{w} / \mathrm{v}) \mathrm{BTH}$ and, when stored under nitrogen at $-20{ }^{\circ} \mathrm{C}$, they were found stable for at least 15 days. Chlorophyll-a and chlorophyll-b standard solutions were prepared as above but with the addition of a known amount of $\beta$-carotene, as a further protection against light and oxidation. Because of the carotenoid instability and tendency to undergo stereomutation, photo and thermolability and easiness toward oxidation, all analytical operations were carried out under dim light and at temperatures not higher than $35^{\circ} \mathrm{C}$. The sample and the standard solutions were stored at $-20^{\circ} \mathrm{C}$ under nitrogen. Solvents contained $0.1 \% \mathrm{BTH}(\mathrm{w} / \mathrm{v})$.

\subsection{Sample extraction}

Ten $\mathrm{ml}$ of non-concentrated orange juice, or $10 \mathrm{ml}$ of tomato puree, or $5.0 \mathrm{~g}$ of tomato paste were generally subjected to the extraction procedure. Instead, in the case of orange juice beverages, $50 \mathrm{ml}$ of product was previously concentrated to a volume of $10 \mathrm{ml}$ and then subjected to the extraction procedure. The samples of green mandarin essential oil were analyzed directly without extracting, after filtration with $0.45 \mu \mathrm{m}$ nylon filters. When extracting carotenoids from Spirulina alga, $1 \mathrm{~g}$ of starting material was found sufficient for the successive analyses.

The samples were introduced into a $250 \mathrm{ml}$ separator funnel and added with $30 \mathrm{ml}$ of dichloromethane/methanol 2:1 (v/v). After shaking, the underlying organic layer was separated. This procedure was repeated until the starting material was colorless. The pooled organic layers were evaporated to dryness at a temperature not higher than $35^{\circ} \mathrm{C}$. When it was necessary to obtain saponification of the carotenoid esters, the residue was suspended in $6 \mathrm{ml}$ of ethyl ether, made up with $6 \mathrm{ml}$ of $10 \%$ $\mathrm{KOH}$ in methanol and allowed to stand for $20 \mathrm{~h}$ in the dark at room temperature. Afterwards, the mixture was transferred into a $250 \mathrm{ml}$ separator funnel, made up with $20 \mathrm{ml}$ of diethyl ether and then with $100 \mathrm{ml}$ of $10 \%$ (w/v) aqueous $\mathrm{NaCl}$. After shaking, the aqueous layer was discarded and the ether layer was washed with water until the washes became neutral to phenolphthalein. Finally, the ether layer was desiccated over anhydrous sodium sulfate and evaporated to dryness.

\subsection{HPLC analysis}

The dried samples obtained from the extraction procedure were dissolved in different volumes of chloroform and filtered through $0.45 \mu \mathrm{m}$ nylon filter immediately before the chromatographic analysis. The HPLC analyses were performed on a Waters Alliance chromatograph equipped with photodiode array detector (PDA) mod. 996. The data were collected by a computer and processed by the Waters Millennium software, 
which operated on the data collected at $450 \mathrm{~nm}$ when analyzing carotens and xanthophylls, and at $428 \mathrm{~nm}$ for the chlorophylls. The analyses were made on a reversed phase column YMC-Pack $\mathrm{C}_{30}(250 \times 4.6 \mathrm{~mm}$ i.d.) filled with $5 \mu \mathrm{m}$ average particle size. The column was thermostated at $30 \pm 0.1{ }^{\circ} \mathrm{C}$. The elution was performed at a flow rate of $1 \mathrm{ml} \mathrm{min}{ }^{-1}$. The injection volume was $10 \mu \mathrm{l}$. The elution was performed with a linear gradient of solvent A (methanol-water, 95:5, v/v, containing BHT 0.1\% and TEA $0.05 \%$ ) and solvent B (methylene chloride, containing BHT $0.1 \%$ and TEA $0.05 \%$ ). The gradient, starting at sample injection, was from $5 \% \mathrm{~B}$ in $\mathrm{A}$ to $70 \% \mathrm{~B}$ in $\mathrm{A}$ in $35 \mathrm{~min}$.

\section{Results and discussion}

Many procedures for extracting carotenoids from a vegetal matrix, in which the cloroplasts of the vegetal cells are predominant, have been reported (for a comparative study see TAUNGBODHITHAM et al., 1998). In these methods different organic solvents, such as tetrahydrofuran (THF), petroleum ether, methanol, acetone, either alone or in mixtures, were employed with or without previous pulp precipitation. Carotens, being highly hydrophobic substances, are better dissolved in apolar solvents such as THF. On the contrary, xanthophylls are better dissolved in more polar solvents, such as methanol. A 2:1 (v/v) dichloromethane/methanol mixture was employed, which is known to extract both neutral and polar lipids with high efficiency (CHEN et al., 1981) and we observed that the vegetal matrices employed were rapidly decolorized by this solution. In fact, in the case of tomato pulp, which strongly retains its pigments, it was observed that two successive treatments with this solvent extracted $98.4 \%$ of the pigments. Also in the case of tomato juice two extractions were sufficient to completely decolorize the product. To avoid the oxidation of carotenoids, which are easily oxidized after extraction from vegetal matrix, $0.1 \%$ BHT was added to the extraction solvent (HART \& SCOTT, 1995).

To estimate the extraction recovery, we used tomato puree with the following carotenoid composition $(\mathrm{mg} / 100 \mathrm{ml})$ : lutein $0.06, \alpha$-carotene $0.03, \beta$-carotene 0.24 , lycopene 28.9. To three identical aliquots of this sample different amounts of lutein, $\alpha$ carotene, $\beta$-carotene and lycopene were added as reported in Table 1. Each measurement was repeated three times. The recovery was $99.1 \%$ for lutein, $99.3 \%$ for $\alpha$-carotene, $98.7 \%$ for $\beta$-carotene and $101.5 \%$ for lycopene.

The extraction mixture, soon after filtration through a $0.45 \mu \mathrm{m}$ nylon filter, was analyzed by HPLC, as reported in Materials and methods chapter, using a reversed phase $\mathrm{C}_{30}$ column with elution gradient made of methanol-water and dichloromethane. 
Table 1

Scheme of the carotenoid addition $(\mathrm{mg} / 100 \mathrm{~g})$ to tomato puree samples for the recovery estimate

\begin{tabular}{lccc}
\hline Sample & 1 & 2 & 3 \\
\hline Lutein & 0.05 & 0.08 & 0.10 \\
$\alpha$-carotene & 0.05 & 0.08 & 0.10 \\
$\beta$-carotene & 0.10 & 0.15 & 0.20 \\
Lycopene & 5.00 & 10.0 & 15.0 \\
\hline
\end{tabular}

This elution gradient was previously employed to separate ergosterol from a complex lipid matrix (DE SIO et al., 2000). Figure 1 reports the chromatograms obtained from the analysis performed on the mixture of the standard compounds. In Fig. 2, a typical chromatogram obtained from a sample of dried tomato is reported. In chromatogram " $\mathrm{b}$ " of Fig. 2, peaks 1, 2, 3 and 4 correspond to lutein, zeaxanthin, $\alpha$-carotene and $\beta$-carotene in the tomato sample. In chromatogram "a" of Fig. 2, the analysis for the quantification of the lycopene (peak 5) in the same tomato sample is reported. This analysis was conducted on the same solution, whose analysis is reported in chromatogram " $\mathrm{b}$ ", and was diluted to 1:30. Lycopene, in fact, is so abundant in tomato, in which it represents about $85 \%$ of the total carotenoids (LEONI, 1993), that a strong dilution is necessary to make its chromatographic peak quantifiable. Unfortunately, the dilution necessary for lycopene analysis is excessive for the other compounds, thus, for the correct quantification of all components, two analyses of the same sample at different dilution are necessary. On the other hand, we found that, especially for lycopene, a suitable dilution is also necessary inasmuch as a marked deviation from the linearity of the instrumental response as a function of lycopene concentration was observed. This is probably due to high light scattering of lycopene solutions also at relatively low concentration. For this reason, only solutions with lycopene concentration lower than $15 \mathrm{ppm}$ were analyzed. Up to this concentration, in fact, the instrumental response was found linear.

As it can be seen in Fig.1, the standard compounds are analyzed with complete resolution in less than $35 \mathrm{~min}$. Due to the rather fast elution gradient employed, another advantage of this chromatographic analysis is that also the most retained compounds, such as lycopene, emerge as sharp peaks. As a consequence, a noticeable increase in the sensitivity ensues. This advantage was already observed when a similar gradient was used for the chromatographic analysis of phospholipids (SERVILLO et al., 1997). 


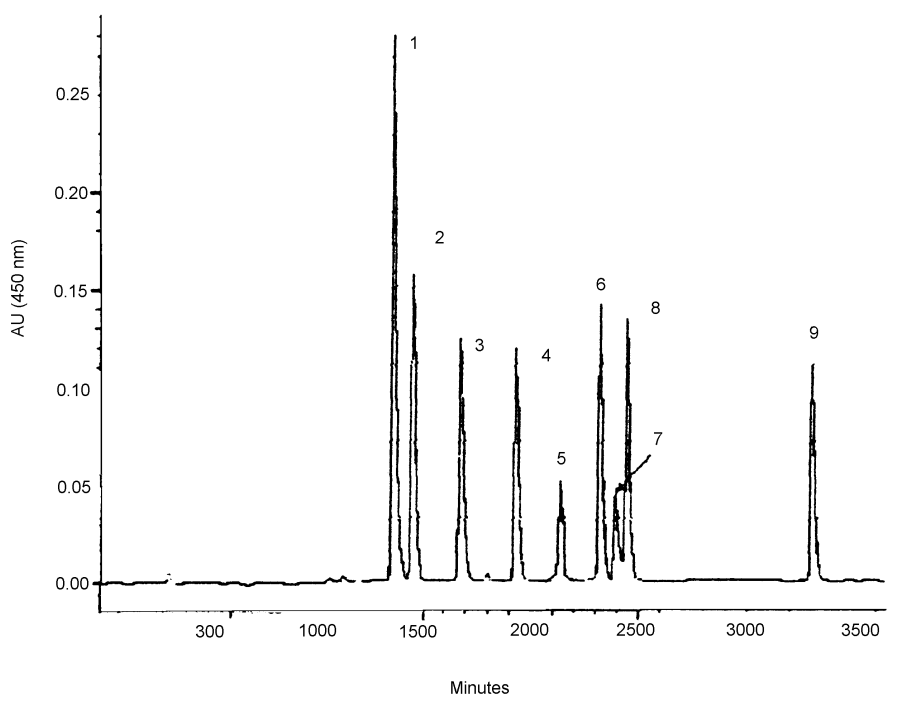

Fig. 1. Reversed phase HPLC separation of carotenoid standard mixture. Peak 1: lutein; peak 2: zeaxanthin; peak 3: trans- $\beta$-apo-8'-carotenal; peak 4: $\beta$-cryptoxanthin; peak 5: chlorophyll-b; peak 6: $\alpha$-carotene; peak 7 : chlorophyll-a; peak 8: $\beta$-carotene; peak 9: lycopene. Chromatographic conditions are reported in Materials and methods chapter

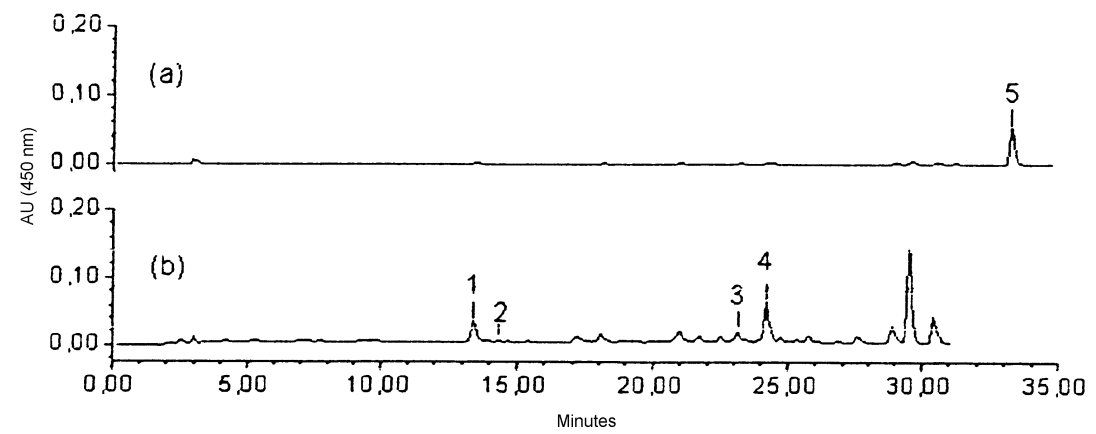

Fig. 2. Reversed phase HPLC analysis of the pigments extracted from a dried tomato sample. The starting solution (chromatographic analysis in chromatogram "b"), was diluted 1:30 to determine lycopene. The chromatogram of the diluted solution is reported in chromatogram "a". The analysis of the starting solution, reported in chromatogram $b$, was interrupted before the elution of the peak 5 , corresponding to the most abundant lycopene, in order to maintain the other components in the same scale. Peak 1: lutein; peak 2: zeaxanthin; peak 3: $\alpha$-carotene; peak 4: $\beta$-carotene; peak 5: lycopene. The component quantification is reported in Table 2 
It is worth to note that, with the gradient we used, the analysis time is noticeably reduced, with no loss of resolution, with respect to the method reported by RouSEFF and co-workers (1996). They used a reversed phase $C_{30}$ column and a rather complex gradient made of methanol, water and MTBE to analyze saponified orange juices carotenoids. In this analysis, the lutein retention time is about $19 \mathrm{~min}$ and $\beta$-carotene retention time is about $39 \mathrm{~min}$. With the gradient we use, the lutein and $\beta$-carotene retention times are about $14 \mathrm{~min}$ and $24 \mathrm{~min}$, respectively. Moreover, in our analysis, lycopene retention time is about $33 \mathrm{~min}$ and, although ROUSEFF and co-workers (1996) did not report the analysis of this compound, it is very likely that, with the gradient they used, the lycopene would emerge from the column as a highly retained broad peak.

Table 2 shows the content of carotenoids in several sources such as vegetables, vegetable industrial products, the blue alga Spirulina and the green mandarin essential oil, measured with the analyses performed as described before.

In order to determine the chromatographic repeatability, the standard mixture (Fig. 1), with the exclusion of the chlorophylls, was injected ten times within two weeks. The chlorophylls were injected five times by preparing the standard solutions just before the analysis. The results are reported in Table 3 . The percent standard deviation $(\% \mathrm{~s})$ calculated for the retention times $\left(t_{\mathrm{r}}\right)$ shows very close values with a maximum of $6.6 \%$ for lycopene, which is the farthest peak and perfectly resolved from the other peaks. The variation coefficient $(\% \mathrm{CV})$, calculated for each peak area, was always lower than $2 \%$. In the case of the peaks corresponding to the two chlorophyll standards, because of the high degradation rate observed for these compounds after dissolution, the \% CV was not determined. Instead, a good stability of the peak corresponding to chlorophyll-a from a sample of the blue alga Spirulina was observed. For this sample, a content of $128.9 \mathrm{mg} / 100 \mathrm{~g}$ with $\mathrm{CV}$ of $1.64 \%$ was calculated from the results of five chromatografic analyses performed over a nine-day period. The same good stability of chlorophyll-a and -b was found for a sample of mandarin essential oil, which gave a CV of $1.96 \%$ for five analyses over a six-day period. The high instability of the pure standards of chlorophyll-a and -b was also observed after dissolving these compounds in other solvents such as ethyl ether or hexane, besides chloroform and dichloromethane. In fact, in the course of successive analyses, a rapid decrement of peak area was observed with a concomitant appearance of new peaks with lower retention times and with absorption spectra different from those of chlorophyll-a and -b. An increment in the stability of the standard chlorophyll solutions was obtained by adding, besides BHT, a known amount of $\beta$-carotene that seemed to exert a protective action.

Generally, when analyzing carotenoids, the sample extraction is followed by a saponification step. This is done in order to hydrolyze carotenoid esters and to remove chlorophylls. However, if the chromatographic procedure separates the chorophylls from the carotenoids of interest, the saponification is unnecessary (HART \& SCOTT, 1995). 
Table 2

The carotenoid content of various sources ( $\mathrm{mg} / 100 \mathrm{~g}$ )

\begin{tabular}{|c|c|c|c|c|c|c|c|c|}
\hline & Lutein & Zeaxanthin & $\beta$-Cryptox. & $\alpha$-Carotene & $\beta$-Carotene & Lycopene & Chlorophyll-b & Chlorophyll-a \\
\hline Artichokes & 0.15 & 0.02 & 0.01 & 0.00 & 0.03 & 0.00 & 0.09 & $<0.01$ \\
\hline $\begin{array}{l}\text { Vegetables } \\
\text { cocktail }\end{array}$ & 0.38 & 0.05 & 0.01 & 1.44 & 2.57 & 0.00 & 0.98 & 0.00 \\
\hline $\begin{array}{l}\text { Eggplants and } \\
\text { peppers }\end{array}$ & 0.70 & 0.13 & 0.21 & 0.40 & 0.96 & 0.02 & 0.65 & 3.39 \\
\hline Dried tomatoes & 0.55 & 0.04 & 0.00 & 0.01 & 1.17 & 35.1 & 0.00 & 0.00 \\
\hline Tomato puree & 0.06 & $<0.01$ & 0.00 & 0.03 & 0.24 & 28.9 & 0.00 & 0.00 \\
\hline $\begin{array}{l}\text { Spirulina } \\
\text { blue alga }\end{array}$ & 0.00 & 5.27 & 0.37 & 0.12 & 9.99 & 0.00 & 0.00 & 128.9 \\
\hline Peaches & $<0.01$ & 0.01 & 0.02 & 0.06 & 0.17 & 0.00 & 0.00 & 0.00 \\
\hline Peaches canned & $<0.01$ & 0.01 & 0.01 & $<0.01$ & 0.12 & 0.00 & 0.00 & 0.00 \\
\hline Olive oil & 0.10 & 0.01 & 0.01 & 0.00 & 0.00 & 0.00 & 0.00 & 0.00 \\
\hline $\begin{array}{l}\text { Yellow orange } \\
\text { juice }\end{array}$ & $\begin{array}{c}0.03 \\
(0.06)\end{array}$ & $\begin{array}{c}0.04 \\
(0.06)\end{array}$ & $\begin{array}{c}0.05 \\
(0.07)\end{array}$ & $\begin{array}{l}<0.01 \\
(0.01)\end{array}$ & $\begin{array}{c}0.03 \\
(0.03)\end{array}$ & $\begin{array}{c}0.00 \\
(0.00)\end{array}$ & $\begin{array}{c}\text { Not } \\
\text { determined }\end{array}$ & $\begin{array}{c}\text { Not } \\
\text { determined }\end{array}$ \\
\hline $\begin{array}{l}\text { Orange based } \\
\text { beverage A }\end{array}$ & $\begin{array}{c}0.05 \\
(0.09)\end{array}$ & $\begin{array}{c}0.08 \\
(0.11)\end{array}$ & $\begin{array}{c}0.05 \\
(0.08)\end{array}$ & $\begin{array}{c}0.01 \\
(0.01)\end{array}$ & $\begin{array}{c}0.04 \\
(0.04)\end{array}$ & $\begin{array}{c}0.00 \\
(0.00)\end{array}$ & $\begin{array}{c}\text { Not } \\
\text { determined }\end{array}$ & $\begin{array}{c}\text { Not } \\
\text { determined }\end{array}$ \\
\hline $\begin{array}{l}\text { Orange based } \\
\text { beverage B }\end{array}$ & $\begin{array}{c}0.04 \\
(0.07)\end{array}$ & $\begin{array}{c}0.06 \\
(0.10)\end{array}$ & $\begin{array}{c}0.15 \\
(0.21)\end{array}$ & $\begin{array}{c}<0.01 \\
(<0.01)\end{array}$ & $\begin{array}{c}0.19 \\
(0.17)\end{array}$ & $\begin{array}{c}0.00 \\
(0.00)\end{array}$ & $\begin{array}{c}\text { Not } \\
\text { determined }\end{array}$ & $\begin{array}{c}\text { Not } \\
\text { determined }\end{array}$ \\
\hline
\end{tabular}

Figure 3 , in fact, shows the chromatographic analysis performed on a green mandarin essential oil. The good resolution of chlorophylls-a and -b peaks from the other carotenoid peaks can be easily seen. However, we employed the saponification step according to ROUSEFF and co-workers (1996) to investigate the possible differences in chromatograms of samples treated with and without the saponification procedure, especially regarding the peak area of lutein, $\alpha$-carotene, $\beta$-carotene and lycopene for tomato products and of zeaxanthin and $\beta$-cryptoxanthin for orange derivatives. 
Table 3

Repeatability of the retention time (\% s) and reproducibility of the peak area (\% CV) of the standard carotenoid mixtures

\begin{tabular}{lcc}
\hline & $\begin{array}{c}t_{R} \\
(\% s)\end{array}$ & $\begin{array}{c}\text { Peak area } \\
(\% \mathrm{CV})\end{array}$ \\
\hline Lutein & 2.08 & 1.62 \\
Zeaxanthin & 2.64 & 1.67 \\
$\beta$-Apo-8'-carotenal & 2.63 & 1.24 \\
$\beta$-Cryptoxanthin & 1.53 & 1.47 \\
Chlorophyll-b & 2.52 & $-^{\mathrm{a}}$ \\
$\alpha$-Carotene & 1.55 & 1.04 \\
Chlorophyll-a & 2.50 & $-^{\mathrm{a}}$ \\
$\beta$-Carotene & 1.53 & 1.81 \\
Lycopene & 6.56 & 1.53 \\
Mean & 2.62 & 1.48 \\
\hline
\end{tabular}

${ }^{\text {a }}$ Not measured.

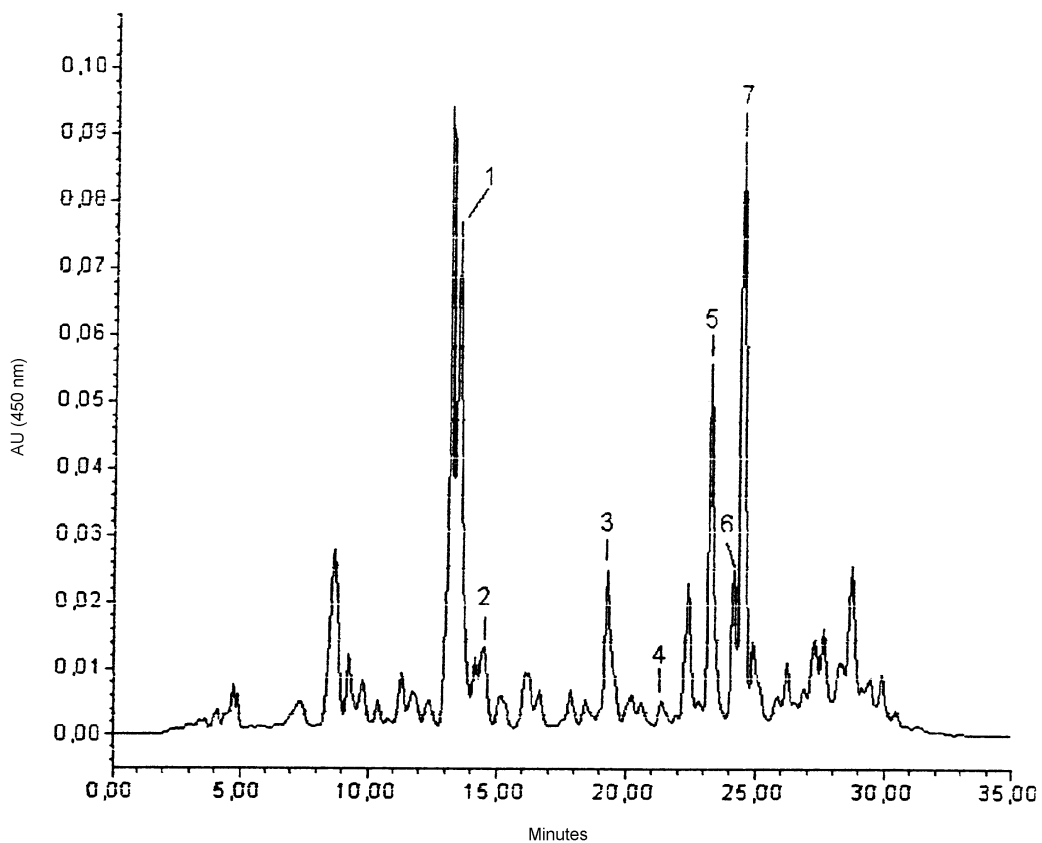

Fig. 3. Reversed phase HPLC analysis of green mandarin essential oil. Peak 1: lutein; peak 2: zeaxanthin; peak 3: $\beta$-cryptoxanthin; peak 4: chlorophyll-b; peak 5: $\alpha$-carotene; peak 6: chlorophyll-a; peak 7: $\beta$-carotene. The essential oil was injected without any treatment. The component quantification is reported in Table 2 
In the case of tomato puree and tomato paste the chromatograms of saponified and nonsaponified samples were found substantially identical. For orange juice and other beverages based on orange juice, after saponification, a mean increment of $100 \%$ for lutein and $50 \%$ for zeaxanthin and $\beta$-cryptoxanthin was found. A similar observation was already reported by WINGERATH and co-workers (1996).

\section{Conclusions}

The procedure described in this paper allows a rapid and sensitive HPLC separation of the main carotenoids present in vegetables. The analysis time appears lower than other reported methods which utilize reversed phase column with elution gradient and, also highly hydrophobic compounds, such as lycopene, are eluted as sharp a peak with rather low retention time. The good resolution obtained with this procedure the chlorophylls from caroteinoids could also allow, in favorable cases, to skip the saponification step of the extracts from the green vegetables to be analyzed for their carotenoid content.

The authors would like to express their gratitude to Ing. D. CACACE of Stazione Sperimentale per l'Industria delle Conserve Alimentari, Angri (SA), Italy, for the support in the statistical analysis of data.

\section{References}

Chen, I. S., Shen, C. S. J. \& ShePPARD, A. J. (1981): Comparison of methylene chloride and chloroform for the extraction of fats from food products. J. Am. Oil Chem. Soc., 58, 599-601.

Conn, P. F., Schalch, W. \& TruscotT, T. G. (1991): Lycopene, (all-E)-rate constant with singlet oxygen. J. Photochem. Photobiol. Biol., 11, 41-47.

De Sio, F., Laratta, B., Giovane, A., Quagliuolo, L., Castaldo, D. \& Servillo L. (2000): Analysis of free and esterified ergosterol in tomato products. J. agric. Fd Chem., 48, 780-784.

Di MASCIO, P., KAISER, S. \& SIES, H. (1989): Lycopene as the most efficient biological carotenoid singlet oxygen quencher. Arch. Biochem. Biophys., 274, 532-538.

Ferruzzi, M. G., SAnder, L. C., Rock, C. L. \& SchwartZ, S. J. (1998): Carotenoid determination in biological microsamples using liquid chromatography with a coulometric electrochemical array detector. Anal. Biochem., 256, 74-81.

FISHER, J. F. \& ROUSEFF, R. L. (1986): Solid phase extraction and HPLC determination of $\beta$-cryptoxanthin and $\alpha$ - and $\beta$-carotene in orange juice. J. agric. Fd Chem., 34, 985-989.

Guillou, A., Choubert, G. \& DE la Noue, J. (1993): Separation and determination of carotenoids, retinol, retinal, and their dehydro forms by isocratic reversed-phase HPLC. Fd Chem., 476, 93-99.

HART, D. J. \& SCOTT, K. J. (1995): Development and evaluation of an HPLC method for the analysis of carotenoids in foods, and the measurement of the carotenoid content of vegetables and fruits commonly consumed in the UK. Fd Chem., 54, 101-111. 
LeONI, C. (1993): I Derivati Industriali del Pomodoro. Stazione Sperimentale per l'Industria delle Conserve Alimentari, Parma, Italy, pp. 23-24.

Levy, J., Bosh, E., Feldman, B., Giat, Y., Munster, A., Danilenko, M. \& Sharoni, Y. (1995): Lycopene is a more potent inhibitor of human cancer cell proliferation than either alpha-carotene or beta-carotene. Nutr. Cancer, 24, 257-266.

Peto, R., Doll, R., Buckley, J. D. \& SpORN, M. B. (1981): Can dietary beta-carotene materially reduce human cancer rates? Nature, 290, 201-208.

Psomiadou, E. \& Tsimidou, M. (1998): Simultaneous HPLC determination of tocopherols, carotenoids, and chlorophylls for monitoring their effect on virgin olive oil oxidation. J. agric. Fd Chem., 46, 5132-5138.

QuACKENBUSH, F. W. \& SMALlidge, R. L. (1986): Non-aqueous reversed-phase liquid-chromatographic system for separation and quantitation of provitamins A. J. Assoc. Off. Anal. Chem., 69, 767-772.

RousefF, R., RALEy, L. \& HofSOMmeR, H. J. (1996): Application of diode array detection with a C-30 reversed phase column for the separation and identification of saponified orange juice carotenoids. $J$. agric. Fd Chem., 44, 2176-2181.

Servillo, L., Iorio, E. L., Quagliuolo, L., Camussi, G., Balestrieri, C. \& Giovane, A. (1997): Simultaneous determination of lysophospholipids by high performance liquid chromatography with fluorescence detection. J. Chromat. B, 689, 281-286.

STAHL, W. \& SIES, H. (1996): Lycopene: a biologically important carotenoid for humans? Arch. Biochem. Biophys., 336, 1-9.

Taungbodhitham, A. K., Jones, G. P., Wahlqvist, M. L. \& BRIgGS, D. R. (1998): Evaluation of extraction methods for the analysis of carotenoids in fruits and vegetables. Fd Chem., 63, 577-584.

Wingerath, T., Stahl, W., Kirsch, D., Kaufmann, R. \& Sies, H. (1996): Fruit juice carotenol fatty acid esters and carotenoids as identified by Matrix-Assisted Laser Desorption Ionization (MALDI) Mass Spectrometry. J. agric. Fd Chem., 44, 2006-2013. 